\title{
Management of subluxated and dislocated lenses with the vitrophage
}

\author{
GHOLAM A. PEYMAN, MOTILAL RAICHAND, MORTON F. GOLDBERG, \\ AND DANIEL RITACCA
}

From the Department of Ophthalmology, University of Illinois Eye and Ear Infirmary, USA

SUMMARY Thirty-two eyes with subluxated and dislocated lenses were surgically managed by means of the vitrophage. The best results were obtained for those cases in which subluxation or dislocation of lenses into the vitreous was not associated with other complications such as glaucoma, perforating injuries, and retinal detachment. No major intraoperative or postoperative problems were seen in uncomplicated cases during a follow-up period ranging from 5 to 45 months.

Management of subluxated and dislocated lenses has remained controversial. The indications for surgical intervention and the procedure of choice are still debatable. Many indications for the removal of dislocated lenses have been described (Haik, 1961; Chandler, 1964; Selleyer and Barraquer, 1973). However, these vary among surgeons. Surgical techniques previously used for removing subluxated or dislocated lenses have included discission, aspiration, lens extraction with forceps or loop, and cryoextraction. Unfortunately these procedures have been associated with a high incidence of operative and postoperative complications (Jarrett, 1967; Barraquer, 1972; Liesman, 1972), such as vitreous loss, retinal detachment, and glaucoma. For this reason many ophthalmologists have considered surgery for dislocated lenses to be very risky and have avoided operating on such eyes.

The automated vitrectomy instruments such as the vitrophage have greatly aided the surgery of the anterior segment. We have previously described the use of this instrument for cataracts in adults and children, for anterior segment reconstruction (Peyman and Sanders, 1975; Peyman, et al., 1975; Peyman et al., 1977; Peyman et al., 1978a, b) and for removal of dislocated lenses through the pars plana route (Peyman and Sanders, 1975). In this report we describe various techniques we have used to deal with dislocated lenses of different types.

\section{Materials and methods}

The surgical management of ectopia lentis depends on the dislocation site and the consistency of the

Correspondence to Dr G. A. Peyman, Eye and Ear Infirmary, 1855 West Taylor Street, Chicago, IL 60612, USA. lens. A total of 32 such eyes (27 patients) were referred to the Vitreous Service of the University of Illinois Eye and Ear Infirmary between 1974 and 1978. These cases were divided into 6 categories, because the management and prognosis varied according to the clinical aspects of each group.

Group a-Subluxation of soft lens behind the pupil. This group was composed of 10 eyes (6 patients). Two patients had Marfan's syndrome; in the rest the subluxation was of unknown aetiology. Except for 1 patient age 30 all were younger than 17 years (range 5-16). All eyes were uninflamed and normotensive. The indications for surgical intervention were impaired vision in 8 eyes and annoying diplopia in 2.

Group b-Dislocation of soft lens into the vitreous. In 12 eyes (12 patients) there was total dislocation of the lens into the vitreous. All had a history of trauma. One patient had diabetes mellitus, and another had a positive serological test result for syphilis. Five eyes had clear corneas and normal intraocular pressures. The other 7 patients had raised intraocular pressures. Of these 7 patients 5 had angle recession and 2 had phacolytic glaucoma. The indications for surgery were raised intraocular pressure in 7 eyes and vitreous opacities in 5 eyes.

Group c-Dislocation of hard lens into the vitreous. Only 1 patient was in this category. An 80-year-old patient fell and dislocated a mature cataract in 1 eye. The cornea showed $1+$ oedema, intraocular pressure was high, and the vitreous had a marked reaction, possibly due to leakage of lens material.

Group d-Lens dislocation associated with perforating ocular injuries and severe ocular trauma. Five eyes (5 patients) had lens dislocation due to perforating corneoscleral injuries. All had total 
detachment of the retina and vitreous haemorrhage. Because of the extensive nature of the ocular trauma these eyes were considered virtually lost preoperatively.

Group e-Dislocation of soft lens into the anterior chamber. Two eyes ( 2 patients) had a dislocation of the lens into the anterior chamber. Both patients had aniridia, corneal oedema and dystrophy, and raised intraocular presure.

Group $f$-Dislocation of hard lens into the anterior chamber. One patient with tertiary syphilis had bilateral dislocation of hard lenses into the anterior chamber with corneal oedema and raised intraocular pressure.

\section{SURGICAL TECHNIQUES}

Group a-Technique of pars plicata lensectomy and vitrectomy for soft subluxated lenses. Sutures are passed through the lid margins for exposure. Then 4-0 silk traction sutures are placed beneath the bellies of the four rectus muscles. A radial peritomy is made in the inferotemporal or superotemporal quadrant and extended in a T-shaped manner along the limbus toward the inferior and lateral recti. After cauterising the episcleral bleeding points, a 4-mm long sclerotomy bed 2.5 to $3 \mathrm{~mm}$ from the limbus is prepared with a No. 15 BardParker blade. When the underlying ciliary body is exposed, it is gently cauterised. A mattress suture is passed through the lips of the sclerotomy and a loose double-throw knot is applied. Either 4-0 or

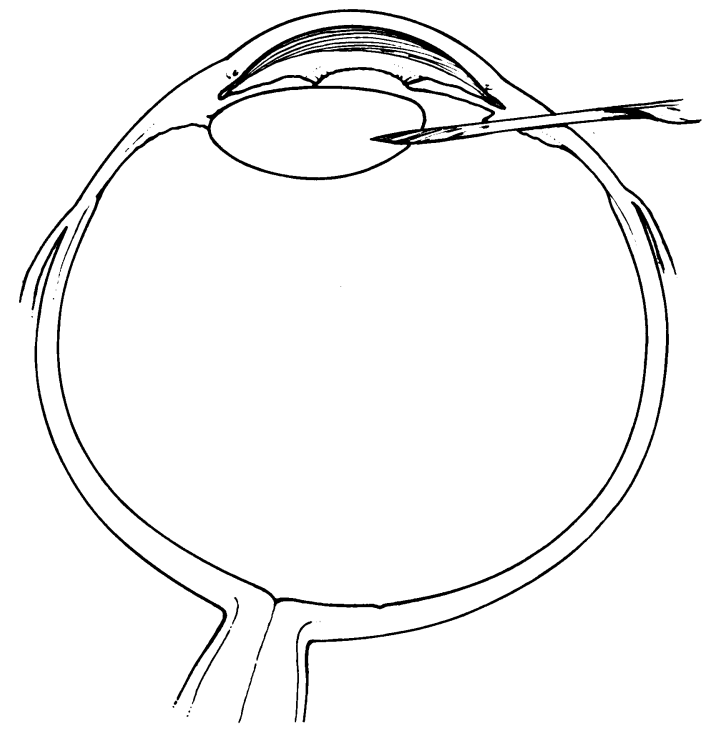

Fig. 1 Schematic diagram of pars plicata approach to remove subluxated lenses. A $52 S$ Beaver knife is inserted through the ciliary body into the lens capsule

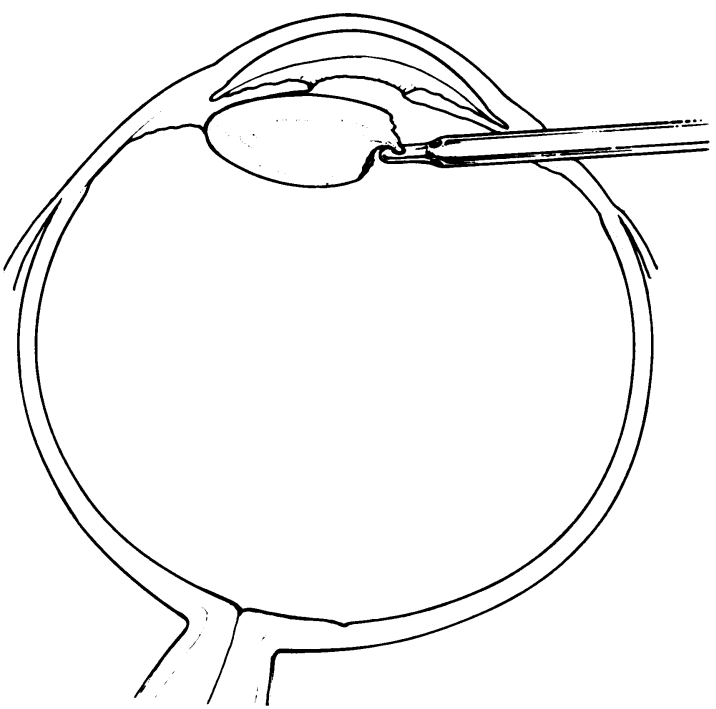

Fig. 2 Vitrectomy instrument is inserted through the knife tract and the soft subluxated lens is removed

5-0 polyglactin 910 (Vicryl) or Supramid suture material can be used for this purpose.

A 52S Beaver blade is passed through the sclerotomy and through the pars plicata into the lens equator, and a track in the lens is made by means of slow slicing motions of the blade. The blade is removed and a wide angle cutter vitrophage (Figs. 1 and 2) is introduced through the sclerotomy into the lens. The mattress suture at the sclerotomy is tightened.

The lens material is cut and removed by the cutting/aspirating tip of the vitrophage. It is essential that the cutting tip is always visible in the pupillary axis. The lens material that is lying behind the iris or ciliary body is brought into the operator's view by indenting the corresponding sclera with a finger tip or cotton-tipped applicator. With the suction function of the vitrophage lens material is brought into view and then cut. The cutting action of the vitrophage is activated only when the cutting port of the vitrophage is in view. This manoeuvre avoids cutting the iris or ciliary processes accidentally. After the lens is removed an anterior vitrectomy is done. At this point a self-infusing fundus contact lens is placed on the cornea. A deep vitrectomy to the optic disc is done. Any lens particles that may have fallen into the vitreous accidentally can easily be retrieved. After completion of the vitrectomy the vitrophage is removed and the sclerotomy suture is tied. Conjunctiva is sutured with 6-0 plain catgut. Atropine and Maxitrol (neomycin and dexamethasone) drops are instilled, and a patch and shield are applied to the eye. 


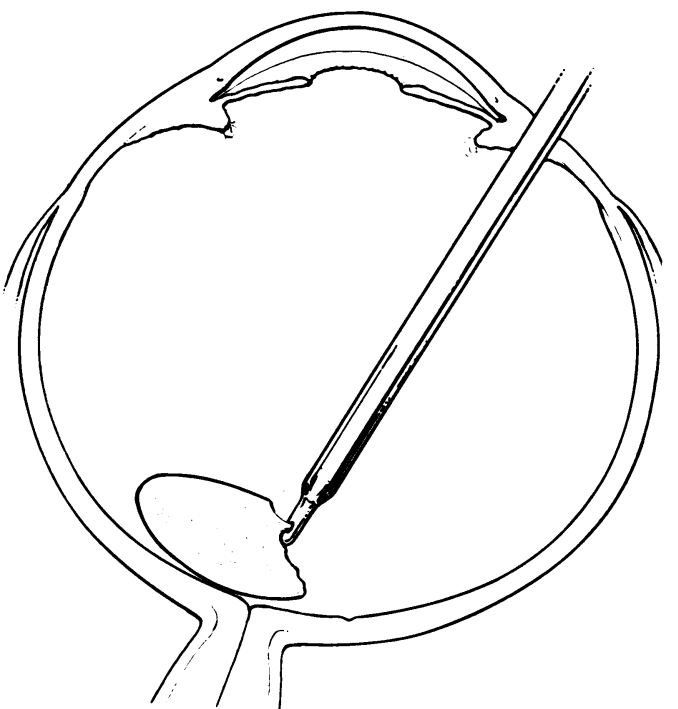

Fig. 3 Schematic diagram of removal of a dislocated soft lens with the vitrophage

On a routine basis an iridectomy (either peripheral or sector) is not necessary. However, when the pupil does not dilate well, a small sector iridectomy can be performed with the cutting action of the vitrophage.

Group b-Management of dislocated soft lens into the vitreous. When a soft lens is dislocated into the vitreous or is lying on the surface of the retina, the initial steps of the technique are the same as for group $a$.

After the vitrophage is inserted into the vitreous cavity an anterior vitrectomy is performed, and the vitreous surrounding the lens is removed. By applying suction it is possible to lift the lens and bring it to the pupillary area, where it can be cut away under direct visualisation (Fig. 3).

At times, in addition to the vitrophage tip, a 25 -gauge needle ( $1 \frac{1}{2}$ inches long) $(3.8 \mathrm{~cm})$ is inserted through the pars plicata at the opposite side of the initial sclerotomy incision (Peyman and Sanders, 1975) (Fig. 4). The lens can be lifted with the tip of the needle, brought into the pupillary area, and removed by the vitrophage.

Group c-Management of hard dislocated lens in vitreous. When the nucleus of the subluxated or dislocated lens is very hard, as in older patients, it is inadvisable to attempt removal of the lens through a posterior approach. These lenses are best removed through a clear corneal incision. The technique involves lifting the dislocated lens with a needle and bringing it into the anterior chamber. The assistant holds the lens pierced by the needle in this position
(Figs. 5 and 6). The assistant also holds the vitrophage in place while infusion is running to prevent collapse of the eye. Then the surgeon performs a clear corneal incision. The lens can be either expressed transcorneally or removed by a cryoprobe.

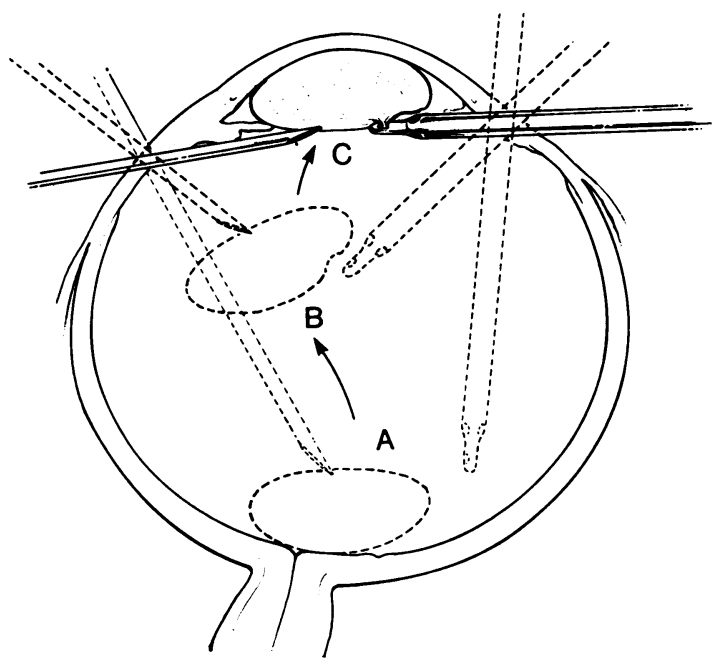

Fig. 4 Two-needle technique of removing lenses of 1 to $2+$ nuclear sclerosis. The needle stabilises the lens while it is cut with the vitrectomy instrument. A. After vitrectomy a 25-gauge needle engages the dislocated lens. B. Lens in midvitreous supported by the needle and vitrophage. C. Lensectomy performed

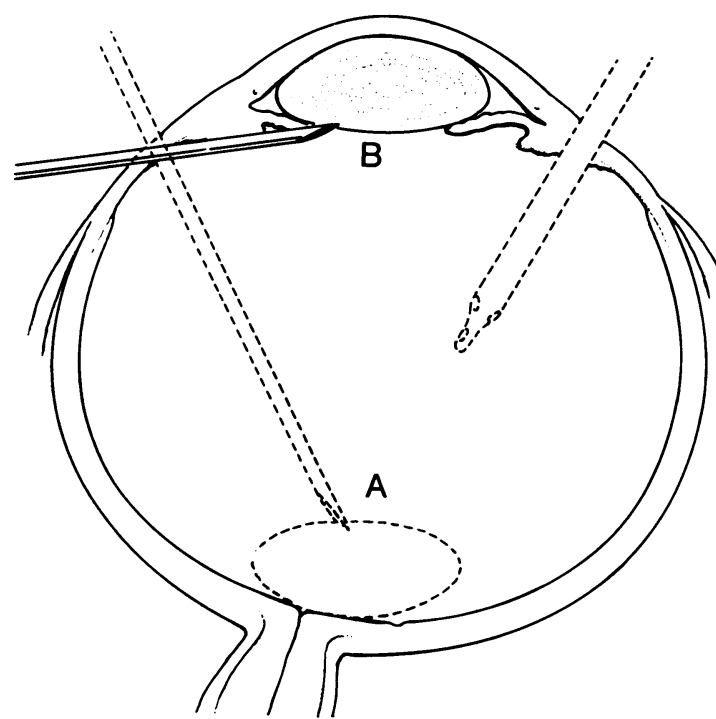

Fig. 5 Removal of dislocated hard lens. A. After vitrectomy the lens is lifted with the tip of a 25-gauge needle. B. Lens is brought into the anterior chamber 
The vitrophage is kept in the eye while this occurs. By keeping the eye infused intraocular pressure can be easily re-established. After closure of the corneal incision (with 9-0 nylon), a vitrectomy is performed (Fig. 7). If the lens is ruptured, lens fragments or capsular remnants can be removed with the vitrophage.

Group $d$-Lens dislocation associated with perforating ocular injuries. The initial step in these cases is to repair the scleral and corneal perforations. A sclerotomy is made in a quadrant that is usually

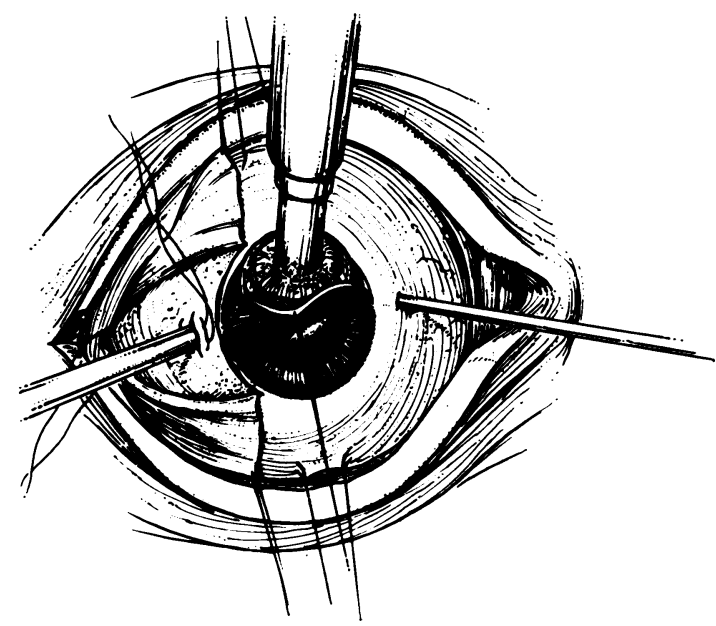

Fig. 6 The vitrophage and the needle remain inside the eye while the dislocated hard lens is removed through a clear corneal incision with a cryoprobe

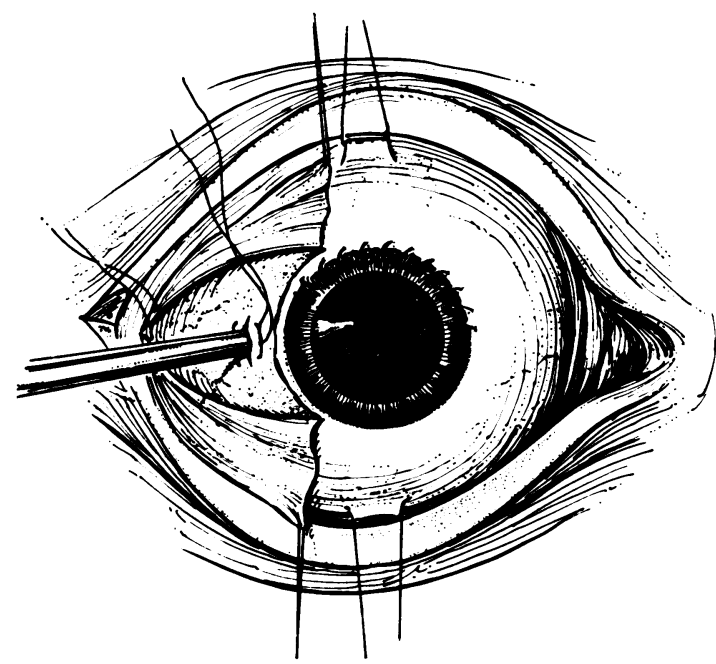

Fig. 7 After closure of the corneal wound and removal of the 25-gauge needle the vitrectomy is completed opposite the quadrant in which the perforation has occurred. Vitrectomy is performed to clear the vitreous haemorrhage and to remove the dislocated lens. Once the media are clear, appropriate retinal surgery is performed.

Group e-Dislocation of soft lens into the anterior chamber. A standard sclerotomy is made in the inferotemporal or superotemporal quadrant, and the vitrophage is inserted as described for group $a$. The pupil should be well dilated so that the vitrophage tip has access to the anteriorly dislocated lens. With the wide angle cutter vitrophage the lens is cut and removed. Then a vitrectomy is performed from the iris plane back to the optic disc.

Group $f$-Dislocation of $a$ hard lens into the anterior chamber. When the crystalline lens is hard and dislocated into the anterior chamber, it is better to remove it through a corneal incision. A standard sclerotomy is performed before the removal of the lens. This is a helpful step, because the eye may collapse during extraction of the lens due to vitreous loss. To perform sclerotomy on a collapsed eye is difficult, and insertion of a vitrectomy instrument through such a sclerotomy can cause detachment of the ciliary body and choroid. After insertion of a 52S Beaver knife through the sclerotomy into the vitreous the sclerotomy is closed temporarily and a clear corneal incision or another type of limbal incision is made. The lens is then removed. After suturing the corneal incision the sclerotomy is opened and a vitrectomy from the iris to the optic nerve is done.

\section{Results}

Group a-Subluxation of soft lens behind the pupil. Excellent surgical results were obtained in all 10 eyes (Table 1a). There were minimal operative complications, namely, limited bleeding in 1 case. The postoperative period, except for transient corneal oedema in 2 eyes, was uneventful. Visual improvement was seen in all cases. However, the visual improvement was minimal in 2 eyes due to amblyopia.

Group $b$-Dislocation of soft lens into the vitreous (Table 1b). Operative results were excellent in the 5 eyes that did not have preoperative glaucoma.

In the 2 eyes with phacolytic glaucoma the intraocular pressure returned to normal between 2 and 3 weeks postoperatively. During that time the intraocular pressure was controlled by medical therapy.

In 5 eyes with angle recession glaucoma the intraocular pressure did not return to normal after surgery. In 2 of these eyes additional surgery was required to control glaucoma; in the other 3 eyes prolonged medical therapy has been necessary. Visual acuity deteriorated in 2 eyes of this group. 
Table 1 Details of cases

\begin{tabular}{|c|c|c|c|c|c|c|c|c|}
\hline $\begin{array}{l}\text { Case } \\
\text { number }\end{array}$ & $\begin{array}{l}\text { Age } \\
(y r)\end{array}$ & $\begin{array}{l}\text { Preoperative } \\
\text { diagnosis }\end{array}$ & $\begin{array}{l}\text { Operative } \\
\text { complication }\end{array}$ & $\begin{array}{l}\text { Postoperative } \\
\text { complication }\end{array}$ & $\begin{array}{l}\text { Preoperative } \\
\text { visual acuity }\end{array}$ & $\begin{array}{l}\text { Postoperative } \\
\text { visual acuity }\end{array}$ & Comment & $\begin{array}{l}\text { Fol } \\
\text { (mo }\end{array}$ \\
\hline \multicolumn{9}{|c|}{ (a) Subluxation of soft lens } \\
\hline 1 & 8 & - & None & None & $20 / 300$ & $20 / 60$ & $\begin{array}{r}\text { Alternating } \\
\text { esotropia }\end{array}$ & 7 \\
\hline 2 & 8 & - & $"$ & , & $3^{\prime} / 200$ & $20 / 40$ & $"$ & 7 \\
\hline 3 & 12 & - & $"$ & " & $4^{\prime} / 200$ & $20 / 50$ & " & 5 \\
\hline 4 & 12 & - & " & $"$ & $20 / 400$ & $20 / 60$ & ” & 5 \\
\hline 5 & 16 & Marfan's syndrome & " & $\begin{array}{l}\text { Transient corneal } \\
\text { oedema }\end{array}$ & $20 / 300$ & $20 / 100$ & Amblyopia & 8 \\
\hline 6 & 7 & - & " & None & $20 / 200$ & $20 / 80$ & $\begin{array}{r}\text { Alternating } \\
\text { esotropia }\end{array}$ & 8 \\
\hline 7 & 7 & - & " & $"$ & Hand motions & $20 / 70$ & " & 7 \\
\hline 8 & 5 & - & $\underset{\text { bleeding }}{\text { Minimal }}$ & $\begin{array}{l}\text { Transient corneal } \\
\text { oedema }\end{array}$ & $20 / 200$ & $20 / 50$ & " & 6 \\
\hline 9 & 5 & - & None & None & $20 / 200$ & $20 / 60$ & $"$ & 6 \\
\hline 10 & 30 & Marfan's syndrome & $"$ & , & $5^{\prime} / 200$ & $20 / 200$ & Amblyopia & 6 \\
\hline
\end{tabular}

(b) Dislocation of soft lens into the vitreous

\begin{tabular}{|c|c|c|c|c|c|c|c|c|}
\hline 1 & 42 & $\begin{array}{l}\text { Uncontrolled } \\
\text { glaucoma, traumatic } \\
\text { dislocated lens, } \\
\text { vitreous touch, } \\
\text { angle recession }\end{array}$ & $\begin{array}{r}\text { Transient } \\
\text { corneal } \\
\text { oedema }\end{array}$ & $\begin{array}{l}\text { Persistent raised } \\
\text { intraocular } \\
\text { pressure }\end{array}$ & Hand motions & Light perception & $\begin{array}{l}\text { Trabeculectomy } \\
\text { done }\end{array}$ & 45 \\
\hline 2 & 54 & $\begin{array}{l}\text { Traumatic dislocation, } \\
\text { corneal oedema, } \\
\text { raised intraocular } \\
\text { pressure, angle } \\
\text { recession }\end{array}$ & - & Phthisis & Hand motions & $\begin{array}{l}\text { No light } \\
\text { perception }\end{array}$ & $\begin{array}{l}\text { Trabeculectomy } \\
\text { done }\end{array}$ & 5 \\
\hline 3 & 60 & $\begin{array}{l}\text { Traumatic dislocation, } \\
\text { angle recession, } \\
\text { raised intraocular } \\
\text { pressure }\end{array}$ & $\begin{array}{l}\text { Mild } \\
\text { bleeding }\end{array}$ & $\begin{array}{l}\text { Raised intraocular } \\
\text { pressure }\end{array}$ & Counting fingers & $20 / 70$ & $\begin{array}{l}\text { Intraocular } \\
\text { pressure con- } \\
\text { trolled with } \\
\text { acetazolamide }\end{array}$ & 9 \\
\hline 4 & 76 & $\begin{array}{l}\text { Angle recession, } \\
\text { traumatic dislocation, } \\
\text { raised intraocular } \\
\text { pressure, choroidal } \\
\text { rupture }\end{array}$ & None & $\begin{array}{l}\text { Transient corneal } \\
\text { oedema }\end{array}$ & Hand motions & $20 / 60$ & $"$ & 6 \\
\hline 5 & 35 & $\begin{array}{l}\text { Phacolytic glaucoma, } \\
\text { traumatic dislocation }\end{array}$ & " & 一 & Counting fingers & $20 / 100$ & - & 11 \\
\hline 6 & 78 & $\begin{array}{l}\text { Traumatic dislocation, } \\
\text { angle recession, } \\
\text { uveitis, raised } \\
\text { intraocular pressure }\end{array}$ & None & None & Counting fingers & $20 / 50$ & $\begin{array}{l}\text { Intraocular } \\
\text { pressure con- } \\
\text { trolled with } \\
\text { acetazolamide }\end{array}$ & 29 \\
\hline 7 & 54 & $\begin{array}{r}\text { Traumatic dislocation, } \\
\text { phacolytic glaucoma }\end{array}$ & "' & $"$ & $20 / 100$ & $20 / 30$ & - & 8 \\
\hline 8 & 11 & Traumatic dislocation & $"$ & $"$ & Counting fingers & $20 / 25$ & 一 & 5 \\
\hline 9 & 32 & Trauma, uveitis & $"$ & $"$ & Hand motions & $20 / 80$ & - & 5 \\
\hline 10 & 14 & Trauma & $"$ & $"$ & Hand motions & $20 / 25$ & - & 5 \\
\hline 11 & 38 & Trauma & $"$ & $"$ & Hand motions & $20 / 70$ & - & 8 \\
\hline 12 & 45 & Trauma & " & " & Hand motions & Counting fingers & $\begin{array}{l}\text { Macular } \\
\text { degeneration }\end{array}$ & 16 \\
\hline
\end{tabular}


Table 1 continued

\begin{tabular}{|c|c|c|c|c|c|c|c|c|}
\hline $\begin{array}{l}\text { Case } \\
\text { number }\end{array}$ & $\begin{array}{l}\text { Age } \\
\text { (yr) }\end{array}$ & $\begin{array}{l}\text { Preoperative } \\
\text { diagnosis }\end{array}$ & $\begin{array}{l}\text { Operative } \\
\text { complication }\end{array}$ & $\begin{array}{l}\text { Postoperative } \\
\text { complication }\end{array}$ & $\begin{array}{l}\text { Preoperative } \\
\text { visual acuity }\end{array}$ & $\begin{array}{l}\text { Postoperative } \\
\text { visual acuity }\end{array}$ & Comment & $\begin{array}{l}\text { Follow-up } \\
\text { (mo) }\end{array}$ \\
\hline \multicolumn{9}{|c|}{ (c) Dislocated hard lens into the vitreous } \\
\hline 1 & 80 & - & None & None & Hand motions & Counting fingers & $\begin{array}{r}\text { Senile macular } \\
\text { degeneration }\end{array}$ & 6 \\
\hline \multicolumn{9}{|c|}{ (d) Lens dislocation with perforating injuries } \\
\hline 1 & 32 & $\begin{array}{l}\text { Corneoscleral lacera- } \\
\text { tion, retinal } \\
\text { detachment }\end{array}$ & None & None & Light perception & $20 / 25$ & - & 9 \\
\hline 2 & 13 & $\begin{array}{l}\text { Corneoscleral lacera- } \\
\text { tion, retinal } \\
\text { detachment }\end{array}$ & , & Phthisis & , & $\begin{array}{l}\text { No light } \\
\text { perception }\end{array}$ & - & 5 \\
\hline 3 & 10 & $\begin{array}{l}\text { Scleral laceration, } \\
\text { dislocated lens, } \\
\text { retinal detachment }\end{array}$ & ", & , & , & , & - & 5 \\
\hline 4 & 27 & $\begin{array}{l}\text { Scleral laceration, } \\
\text { dislocated lens, } \\
\text { retinal detachment }\end{array}$ & " & " & , & , & -- & 8 \\
\hline 5 & 59 & $\begin{array}{l}\text { Corneoscleral lacera- } \\
\text { tion, retinal } \\
\text { detachment }\end{array}$ & " & - & , & , & - & 9 \\
\hline \multicolumn{9}{|c|}{ (e) Dislocation of soft lens into the anterior chamber } \\
\hline 1 & 61 & $\begin{array}{l}\text { Aniridia, corneal } \\
\text { dystrophy, raised } \\
\text { intraocular pressure, } \\
\text { cupped disc }\end{array}$ & None & None & Hand motions & Light perception & - & 6 \\
\hline 2 & 28 & , & , & ", & Counting fingers & $2^{\prime} / 200$ & - & 6 \\
\hline \multicolumn{9}{|c|}{ ( $f$ ) Dislocation of hard lens into the anterior chamber } \\
\hline 1 & 48 & $\begin{array}{l}\text { Corneal oedema, } \\
\text { tertiary syphilis, } \\
\text { raised intraocular } \\
\text { pressure }\end{array}$ & None & None & Counting fingers & $5^{\prime} / 200$ & - & 10 \\
\hline 2 & 48 & , & " & " & Light perception & $10^{\prime} / 200$ & - & 10 \\
\hline
\end{tabular}

Group c-Dislocated hard crystalline lens into the vitreous (Table 1c). After surgery the intraocular pressure gradually returned to normal during a period of 3 weeks. There were no complications during surgery and the postoperative period. Final visual acuity was only counting fingers owing to senile macular degeneration.

Group $d$-Lens dislocation associated with perforating ocular injuries (Table 1d). Because of the extensive nature of injuries only 1 eye of the 5 could be salvaged. Visual acuity was reduced to no light perception in 4 eyes. Three of these eyes became phthisical.

Group e-Dislocation of soft lens into the anterior chamber (Table 1e). Both lenses were removed successfully. Because of the decompensated state of the cornea, raised intraocular pressure, and optic atrophy, visual improvement was minimal in one case and vision worsened in the other case. There were no complications during surgery.

Group f-Dislocation of hard lens into the anterior chamber (Table If). Visual acuity improved, but improvement was limited because of coexistent corneal pathology and glaucoma. There were no surgical complications.

\section{Discussion}

Management of ectopia lentis presents a perplexing problem for many ophthalmologists. There is a continuing debate between proponents of active surgical intervention and advocates of conservative treatment. The latter group cite cases in which dislocated lenses have been tolerated well with maintenance of good vision for many years. Although this is true in many instances, other cases 
require lens removal for optical purposes or for relief of phacolytic glaucoma.

With the availability of automated vitrectomy instruments the much dreaded complication of vitreous loss and its subsequent sequelae can be avoided. Through a small incision a vitrectomy can be done at the time the lens is removed.

In the past the major concern in management of subluxated and dislocated lenses has been the occurrence of operative and postoperative complications, mainly those due to vitreous manipulation. In a large series reported by Jarrett (1967), for example, there was an incidence of vitreous loss of $41 \%$, and one-third of these eyes became blind. Retinal detachments occurred in about $7 \%$ of the cases.

Jensen and Cross (1972) reported a 30\% incidence of vitreous loss during surgery in patients with Marfan's syndrome. Surgical techniques included discission, aspiration, and intra- or extracapsular extraction. In one-fourth of these eyes retinal detachment subsequently developed. Similar complications were seen in patients with homocystinuria, and vitreous loss occurred in $30 \%$ of these cases. The surgical procedures included aspiration, discission, and intracapsular extraction. Retinal detachment was noted in $11 \%$. Other complications included corneal oedema and iris prolapse. In a large series reported by Selleyer and Barraquer (1973) vitreous loss occurred in 15 of 222 eyes. The surgical techniques used were aspiration and intra- or extracapsular extraction.

The technique of lens aspiration (Maumenee and Ryan, 1969) has been associated with a lower incidence of complications. However, in some cases a secondary discission of pupillary membranes is required. Realising the importance of the vitreous, other surgeons have advocated open-sky vitrectomy before and after lens removal. Croll and Croll (1975), employing open-sky vitrectomy, reported excellent results with cryoextraction of 22 dislocated lenses. Barraquer (1972) also used an open-sky vitrectomy technique to complement cryoextraction.

To avoid confusion we use the term 'subluxation' to imply partial dislocation and 'dislocation' to mean total displacement. In our series excellent surgical results were obtained in all 10 cases of subluxated lenses. There were no significant operative or postoperative complications. In most cases the visual improvement was dramatic. In the eyes where final visual acuity was impaired due to the presence of amblyopia annoying symptoms of monocular diplopia were eliminated.

In our series trauma caused 12 cases of total dislocation of soft lenses into the vitreous. Good surgical results were obtained in 10 eyes. Except for transient corneal oedema and minimal bleeding there were no significant operative complications. Eyes with phacolytic glaucoma returned to normal intraocular pressure after lensectomy and vitrectomy. However, eyes with traumatic angle recession glaucoma did not do so well. Rosenbaum and Podos (1967) reported on a series of 27 cases of traumatic dislocation of lenses. Of these, $15(56 \%)$ had raised intraocular pressure preoperatively. One of these was due to phacolytic glaucoma, and others were due to angle recession and peripheral anterior synechiae. Intracapsular lens extraction was attempted on 13 in this group. There was vitreous loss in 11 cases $(84 \%)$. Seven eyes $(54 \%)$ had postoperative vision of counting fingers or less. In Jarrett's series (Jarrett, 1967) there were 31 cases of traumatically dislocated lenses associated with glaucoma. Removal of lenses in 24 eyes led to control of glaucoma in only 6 eyes. The other 7 cases were managed conservatively. Rodman (1963) studied histopathologically a series of eyes that had been enucleated because of glaucoma and a dislocated lens. Postcontusion deformity of the chamber angle was seen in $95 \%$ of those eyes that had glaucoma and an open angle. The efficiency of lens removal in the management of angle recession depends therefore upon the state of the angle.

Dislocation into the vitreous of a lens with a hard nucleus occurred in only 1 case in our series. This was successfully removed through a clear corneal incision, while the vitrophage tip was maintained in the vitreous through a sclerotomy.

Our visual results were poor when lens dislocation was associated with perforating injuries, although vitrectomy and lensectomy helped to clear the media and reform the globes. Because of damage to the ciliary body and the retina (often with inoperable retinal detachment), the majority of the eyes could not be saved.

Anteriorly dislocated lenses can be managed through the pars plicata or pars plana if the lens is soft. If the lens is hard, it should be removed through a clear corneal incision. In our series the postoperative results depended on the preoperative status of the cornea and presence of glaucoma or retinal changes. There were no complications as a result of surgery.

We now have postoperative follow-up of subluxated and dislocated lenses for a period ranging from 5 to 45 months. The early postoperative complications were directly related to pre-existing conditions of the eyes, such as corneoscleral laceration, retinal detachment, or uncontrollable glaucoma. We have not observed significant adverse changes late in the follow-up period. Although longer follow-up is desirable, the present results can 
be considered very encouraging. We believe that a 1-stage pars plicata or pars plana lensectomy and vitrectomy is an ideal procedure for the management of those subluxated or dislocated lenses that require removal.

This work was supported in part by core grant 1P30EYO1792 and training grant EY703802 from the National Institutes of Health, Bethesda, Maryland, and the Lions of Illinois Foundation.

\section{References}

Barraquer, J. (1972). Surgery of the dislocated lens. Transactions of the American Academy of Ophthalmology and Otolaryngology, 1976, 44-59.

Chandler, P. A. (1964). Choice of treatment in dislocation of lens. Archives of Ophthalmology, 7, 765.

Croll, M., and Croll, L. J. (1975). Cryoextraction of dislocated lens. Annals of Ophthalmology, 12, 45-52.

Haik, G. M. (1961). Subluxation and luxation of the lens. Southern Medical Journal, 54, 642.

Jarrett, W. M. (1967). Dislocation of the lens. Archives of Ophthalmology, 78, 289.

Jensen, A. D., and Cross, H. E. (1972). Surgical treatment of dislocated lenses in the Marfan syndrome and homocystinuria. Transactions of the American Academy of Ophthalmology and Otolaryngology, 76, 1491.

Liesman, N. (1972). Congenital cataract and ectopic lentis: an analysis of 152 patients treated in 1943-1967. Acta Ophthalmologica, Suppl. 112, 13-79.
Maumenee, A. E., and Ryan, S. (1969). Aspiration technique in the management of the dislocated lens. American Journal of Ophthalmology, 68, 808-811.

Peyman, G. A., Huamonte, F. J., and Goldberg, M. F. (1975). Management of cataracts in patients undergoing vitrectomy. American Journal of Ophthalmology, 8, 30-36.

Peyman, G. A., Huamonte, F. U., Goldberg, M. F., Sanders, D. R., Nagpal, K. C., and Raichand, M. (1978a). Four hundred consecutive pars plana vitrectomies with the vitrophage. Archives of Ophthalmology, 96, 45-50.

Peyman, G. A., Raichand, M., and Goldberg, M. F. (1978b). Surgery of congenital and juvenile cataracts: a pars plicata approach with the vitrophage. British Journal of Ophthalmology, 62, 780-783.

Peyman, G. A., and Sanders, D. R. (1975). Advances in Uveal Surgery, Vitreous Surgery and the Treatment of Endophthalmitis, p. 113. Appleton-Century-Crofts: New York.

Peyman, G. A., Sanders, D. R., Rose, M,, and Korey, M. (1977). Vitrophage in the management of congenital cataracts. Albrecht von Graefes Archiv für klinische und experimentelle Ophthalmologie, 202, 305.

Rodman, H. I. (1963). Chronic open angle glaucoma associated with traumatic dislocation of the lens: a new pathogenetic concept. Archives of Ophthalmology, 69, 445-454.

Rosenbaum, L. J., and Podos, S. M. (1967). Traumatic ectopia lentis: some relationships to syphilis and glaucoma. American Journal of Ophthalmology, 64, 1095-1098.

Selleyer, L. F., and Barraquer, J. (1973). Survey of etopic lens. Annals of Ophthalmology, 5, 1127-1135. 